\section{The oldest pregnant mum}

Researchers in Australia have uncovered the oldest record of live birth - viviparity - in any vertebrate (see page 650). The discovery of embryos in fossils of placoderms (ancient, armoured, jawed fish) indicates that vertebrates have been copulating and giving birth to live young for at least 380 million years.

"We've discovered the world's oldest [pregnant] mother," says palaeontologist John Long at Museum Victoria in Melbourne, Australia, who led the study. Previously, the earliest records of viviparity were from marine reptiles from the Jurassic period that date back to around 180 million years ago, he says.

The fossils are from the Gogo Formation, a one-time coral reef in northwest Australia that is renowned for its remarkably wellpreserved fish from the Devonian period, some 380 million years ago. The region is tectonically stable, so specimens have been spared the movements of Earth's plates that often distort fossils. "Gogo fish are three-dimensional, uncrushed, perfect specimens - as if they

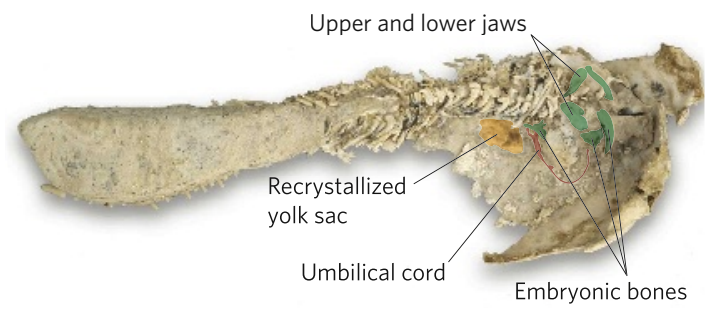

A placoderm fish containing an embryo.

died yesterday," says Long. Soft tissues, including muscle and nerve structures, have been reported in Gogo specimens (K. Trinajstic et al. Biol. Lett. 3, 197-200; 2007).

The researchers identified a single embryo in a new Gogo fish genus, and three embryos in a previously described specimen. "When you find a little fish inside a big fish, you tend to think it was dinner," Long says. But the researchers concluded that the bones were those of embryos, not ingested remains, because they were not crushed or etched by digestive acids. What nailed it, according to Long, was the identification of an umbilical structure and a putative yolk sac.

Palaeontologists will be excited but not completely surprised by the findings, because many suspected that some placoderms fertilized internally. The males of a sub-group of placoderms, called ptyctodontids, have clasper-like appendages dangling from their pelvic fins these are reminiscent of the claspers of modern sharks that are used to inseminate females.

"Internal fertilization does not have to mean viviparity, because some sharks and rays lay their eggs after they have been fertilized internally, but with the discovery of the embryos we can now be sure that at least some placoderms gave birth to live young," says palaeontologist Per Ahlberg at Uppsala University in Sweden.

Most modern fish opt for high-volume procreation, spawning masses of eggs, few of which survive. Placoderms, however, seem to have a similar reproductive strategy to that of some modern sharks and rays, investing in a few progeny and rearing them internally before releasing them as well-developed juveniles.

Placoderms are the first branch of jawed vertebrates and are thought to be a sister group of the common ancestor to both sharks and bony fish - viviparity is thought to have evolved independently in these different vertebrate lineages. The new discovery is important, Ahlberg says, because placoderms are completely extinct, unlike other evolutionary branches that have living descendants from which functional and structural information can be inferred.

"Our ongoing investigations suggest that viviparity is more widespread than previously thought in early placoderms," says Long, alluding to current efforts to scan other Gogo specimens for embryos. Indeed, one of the Gogo species from the current paper was first described by Long two decades earlier, but he had mistaken the embryos for an unusual cluster of external scales. "In earlier studies of placoderms, remnants of young have been observed inside adults and it was assumed to be cannibalism. Now we will have to look more carefully," says palaeontologist Philippe Janvier of the National Museum of Natural History in Paris.

Michael Coates, a palaeontologist at the University of Chicago, Illinois, predicts that there will be some debate over the soft-tissue preservation and whether the presumed yolk sac is a true structure. "It raises questions over the range of possible maternal-feeding strategies," Coates adds. Sharks use various strategies for supplying nutrients to their embryos, including secreting nutrients from the lining of the oviducts, or releasing unfertilized yolk-containing eggs for the embryos to consume.

Sharks have an elaborate and violent courtship, and these findings raise titillating speculation over placoderm sexual behaviour. "These early primitive fish, which were thought to be big, slow, dull, armoured fish, probably had an amazing courtship ritual," says Long.

Carina Dennis
ON THE RECORD

\section{"He's the best when it comes to dog cloning, and for that reason it behoves us to work with him."}

Lou Hawthorne, chief executive of BioArts International in Mill Valley, California, explains why his company has partnered with disgraced South Korean scientist Woo Suk Hwang to clone pet canines. The bidding for the first five dog duplications will start next month at US\$100,000.

\section{ROBOT NEWS}

\section{Robobunny}

Researchers on two continents have made major advances towards developing robotic rabbits. In British Columbia, a scientist has built a therapeutic bunny that responds to petting. Meanwhile, a Swiss team has developed a microbot that hops hither and thither. Next step: designing an automaton fuelled by lettuce.

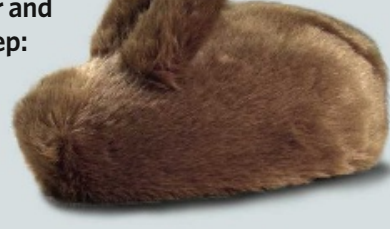

\section{SHOWBIZ NEWS}

Indiana Jones and the wax crusade Harrison Ford feels the planet's pain. Literally. The 65-year-old actor had his chest waxed to highlight how deforestation hurts the Earth's environment. Ford has had a busy month: he has been elected to the board of the Archaeological Institute of America and apparently also has a new film out.

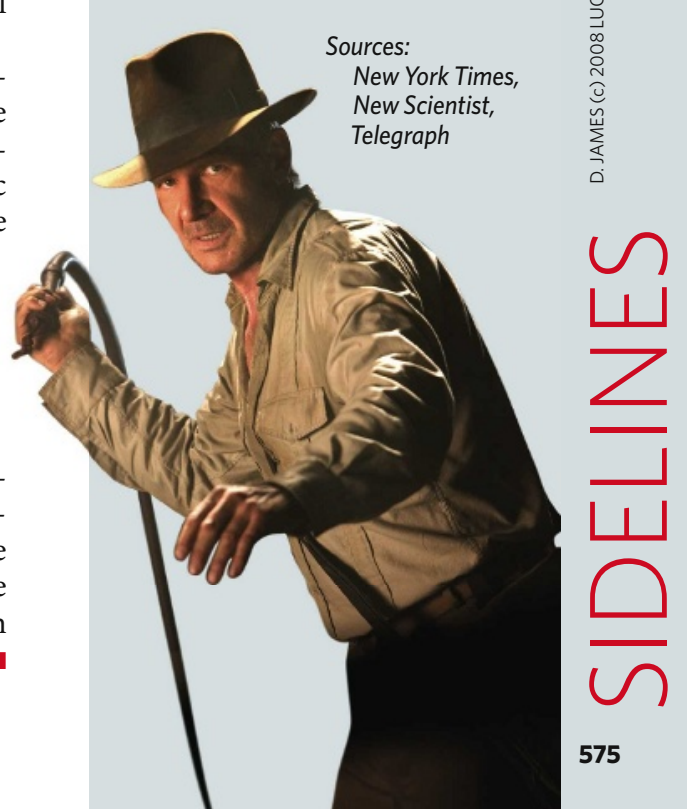

